\title{
Study on Teaching Reform of Higher Mathematics in Economics and Management Specialty
}

\author{
Linyuan Fan \\ School of Statistics, Capital University of Economics and Business, Beijing 100070, China; \\ fanlinyuan@cueb.edu.cn
}

Keywords: Higher mathematics; Teaching reform; Economics and management specialty.

\begin{abstract}
This paper analyzes the current situation of Higher mathematics curriculum and the problems in teaching, and discusses the goal orientation of higher mathematics teaching reform of students major in economics and management in combination with the teaching practice in recent years. To improve mathematics teachers 'economic and management expertise, cultivate students' initiative, improve teaching methods, strengthen mathematical modeling teaching and construct scientific evaluation system, we put forward some reform ideas and measures.
\end{abstract}

\section{Introduction}

Higher mathematics is an important theoretical course offered by institutions of higher education. It is an essential course for the follow-up courses of students in economic and management specialty and the basic course of scientific research. Through the study of higher mathematics, not only can students get the basic idea of basic calculus knowledge, basic computing skills and application methods, but also for students to learn the follow-up courses and later research and application to provide the necessary mathematical basis. Through the corresponding teaching links, and gradually develop students' rational thinking, logical thinking, abstract thinking and analysis of problems and problem-solving skills, so that students can use mathematical methods to analyze and solve the economic and management disciplines in the field of practical problems. At the same time, the higher mathematics curriculum plays an important role in cultivating the comprehensive quality and innovation consciousness of the students of economic management. Because of this, we have to continue to explore, practice and reform the teaching of higher mathematics in economics and managements specialty.

\section{Current Situation of Higher Mathematics Courses in Economics and Management Specialty}

As a college specialty in economics and management professional, higher mathematics set up a compulsory course to improve students' mathematical knowledge and mathematical ability played an important role. However, in recent years, the teaching process has also found that some students are not very enthusiastic about learning, using mathematical knowledge and mathematical ideas to solve the problem of economic management is not very strong. Through the investigation and analysis, I believe that the main reasons for the following:

Firstly, the purpose of learning is not clear enough. Some students believe that the content of higher mathematics courses is boring, spending a lot of energy and time still cannot fully understand the true meaning of the higher mathematics knowledge, or learning role in the follow-up course.

Secondly, the teaching content and timing of higher mathematics courses are not appropriate, lack of organic communication with economic management knowledge. The content of higher mathematics teaching in economic and management specialty is basically the streamlining and compression of higher mathematics teaching content of science and engineering specialty. In the teaching process, a large number of basic knowledge of mathematics taught to students, by the time limit must be streamlined and compressed content. Therefore, traditional teaching methods focus on conclusions, knowledge and applications but not proof, thought or deductions. 
Thirdly, the teaching evaluation method is single. At present, the evaluation method of learning the effect of higher mathematics course is generally examination. The main contents of the examination are mathematics basic knowledge and mathematical computing ability. Some students in order to cope with the exam, just for the examination content to study and review, or even rote, through hard study, although some students have mastered a lot of mathematical knowledge, but in the understanding of mathematical knowledge and application of the ability to improve the effect is not obvious. Some students are only studying in order to cope with the exam, simply cannot talk about the real digestion, understanding and absorption, almost no improvement in mathematical ability.

\section{Problems of Higher Mathematics Courses in Economics and Management Specialty}

\subsection{Lack of Organic Combination between Teaching Content and Economic and Managemental Application.}

According to the teaching purpose of higher mathematics, the teaching task of higher mathematics in economics and management specialty is: first, to master the basic knowledge of differential and integral, the basic thinking method; second, for students to follow the course, future research and application Provide the necessary mathematical tools. However, from the existing higher mathematics textbooks, it cannot meet the actual requirements of economic management professional. At present, most of higher mathematics teaching materials is theoretical, the content is only the science and technology of higher mathematics teaching materials compression and simplification to the formula, the theorem of the main introduction, and economic management disciplines are not closely integrated. This kind of teaching material, the lack of practicality for the students, it is not only boring and difficult to understand, but also increase the difficulty for the teaching of teachers, while dampening the enthusiasm of students in learning. The common problems of these teaching materials are: on one hand, too much emphasis on the rigor of mathematics and the rigor of mathematical thinking, focusing on deduction, reasoning and computing skills, and the application of mathematical ideas and methods to analyze the problem, but practical problems combined with practical examples and economic management are few. On the other hand, it is difficult to see the application of mathematical knowledge in the teaching materials to establish mathematical models, data mining, scientific analysis, judgment and demonstration, to solve practical problems in economic management examples, the lack of depth and breadth, difficult to develop students' skills to solve the practical problems.

\subsection{Content of higher mathematics and middle school are out of touch.}

With the reform of mathematics textbooks in middle schools in recent years and the liberal arts of secondary schools, in the middle school stage, some knowledge is required to reduce. For liberal arts, even some knowledge was deleted. Trigonometric and inverse trigonometric functions of the teaching requirements to reduce the polar and complex and other content was deleted. In addition, the contents of the syllabus of different provinces and cities are not the same, some high mathematics concept in the middle school teaching content also appeared. However, although the content of higher mathematics has also been revised and reformed several times, but the content of the basic requirements of the students still remain in more than a decade ago. So, when the students from the secondary school came into the university, there are some knowledge of blind spots, it is much more difficult for learning.

\subsection{Faculty construction needs to be further strengthened, teaching methods and methods need to be further improved.}

As the economics and management professional math teachers are math professional background, the economic and management professional knowledge is not enough, in the mathematics and economic management disciplines of the application of the organic combination of teaching is very weak, most teachers are only satisfied with teaching mathematics content and knowledge, in teaching rarely reflect the application of mathematics in economic and management. In addition, most of the teachers are still using the 'indoctrination' teaching methods, mainly in the classroom to teach the 
main teachers, students passively follow the teacher's thinking ideas, teachers explain too much, students think too little, students learn to take the initiative is not fully demonstrated in the teaching process, not fully integrated into the teaching process. These factors lead to students feel that high mathematics learning is difficult, can not see the wonderful application of mathematics, affecting the initiative and enthusiasm of students to learn.

\subsection{Students Do Not Have a Strong Foundation of Mathematics, and Some Deficiencies in Learning Methods.}

With the increasing number of university admissions, the proportion of university admission is getting higher and higher, university education decreases from elite education gradually to popular education. Many colleges and universities of economic and management professional and scientific and cultural income, some poor mathematics students into the economic and management professional, such that students of the mathematical foundation of the gap is increasing. However, higher mathematics teaching is generally a large class, is not conducive to the implementation of hierarchical teaching method. Higher mathematics is an abstract, logical and reasoning precise course, some students who are not good in the learning method, not good at summing up, can not learn by analogy. In addition, some students learn to take the initiative, the lack of hard-working spirit, lack of self-control, and even a small number of students wear tired and fear of distress, often absenteeism, to higher mathematics teaching increased difficulty, affecting the teaching effect.

\section{Measures of Higher Mathematics Teaching Reform in Economic Management Specialty}

\subsection{Strengthen the Construction of Teaching Materials, Optimize the Teaching Content.}

With the development of economic and management disciplines, the basic requirements of higher mathematics teaching in economic and management should follow the principle of "mathematics as the basis, economic and management as the fundamental, application for the purpose" principle. In the higher mathematics teaching materials of economic and management specialty, the knowledge of mathematical theory should follow the "moderate enough" principle. Fully consider the teaching purposes, to ensure the rigor of mathematics knowledge, logical premise, should be deleted or simplified unnecessary reasoning demonstration process, which is more conducive to the mastery of students and understanding. The construction of teaching materials should pay attention to the theory and practice, pay attention to the higher mathematics knowledge and solve the practical problems in the field of economic management together, emphasizing the emergence and application of mathematical knowledge background, pay attention to cross-integration of different disciplines. Combined with the economic and management professional needs of mathematics, highlighting the example of teaching ideas. The purpose of mathematics teaching is to cultivate students' ability to apply mathematical knowledge to solve practical problems. Therefore, the introduction of the concept, the proof of the theorem, and so on are starting from the actual background as much as possible, and the process of reasoning is too complicated and unnecessary. Accurate language description and the combination of the number of methods to help students to master and understand, and enable students to understand the concept of mathematics, mathematical theory of the discovery and development process, to cultivate students innovative thinking is very useful.

\subsection{Strengthen the Abilities of Teachers, So That Teachers Master Economic and Management Expertise.}

In order to cultivate students' ability to solve the problems of economic management, the quality of teachers should be improved with the deepening of teaching reform. Economics and management professional mathematics teachers not only to be skilled in the professional knowledge, but also to understand and master some of the economic management professional knowledge, the only way to better teach the economic management of mathematics courses, to further improve the quality of teaching. On one hand, math teachers can communicate with the teachers of economic and management specialty and understand the requirements of economic and management specialty, and focus on the teaching. On the other hand, mathematics teachers should learn some economic and management theories and methods, mathematical model related to economic and management 
specialty, such as storage model, the optimal price model, spider model, and so on. Through learning and communication, comprehend the link between mathematics and economic management, master new knowledge and new concepts, improve their own level of economic and management professional knowledge, promote higher mathematics teaching reform, improve teaching quality in economic management specialty.

\subsection{Cultivate Students 'Interest in Learning, and Mobilize Students' Positive and Active Learning.}

Interest is the most effective learning motivation, students can learn high mathematics, which depends on the enthusiasm of learning mathematics. This enthusiasm is not only based on a true understanding of the basis of mathematics, but also requires teachers to pay attention to the cultivation of students' interest in learning. In the teaching process, you can introduce the history of mathematics and the mathematician's stories and the application of calculus, on one hand so that students can understand the development of mathematics, understand the hard work of mathematicians, to understand the high mathematics in various fields play an important role, and students fully feel the vivid and practical mathematics; on the other hand, can also stimulate students to study hard. In the daily study, teachers should be pay more attentions to communication with students, give students some encouragement and affirmation and guide students, so that students can understand the process of learning mathematics is to develop their own thinking ability, improve their quality of the process, moreover the basis for learning specialized courses and conducting research. Teachers should actively help students to clearly study the purpose, correct learning attitude, improve the interest in learning mathematics, so that students could learn with good mathematical confidence.

\subsection{Improve Teaching Methods, Optimize Teaching Methods.}

For teaching institutions of universities, the purpose of education is to cultivate applied talents. In the course of teaching the higher mathematics of economics and management specialty, teachers should fully tap the students' potential and cultivate students' ability to apply mathematics to solve practical problems according to the teaching principle of "applying for purpose". In the teaching methods, students should give full play to the main position in teaching, to mobilize the enthusiasm of students. Teaching as far as possible with specific examples, weaken the abstraction of mathematics, so that students feel the role of learning mathematics. According to the characteristics of college students, in the classroom teaching can take a flexible and diverse teaching methods, such as organizing classroom discussions, teachers to ask specific questions, so that students discuss and eventually propose solutions, and so on. This kind of teaching method is open, can increase the interest of learning, active classroom atmosphere, mobilize the enthusiasm of students, change the teacher-centered teaching mode, so that students really become the main body of teaching, teachers and students to achieve interaction, give full play to students' subjective initiative, really play the role of teaching and learning. In the classroom teaching, try to use heuristic teaching methods to develop students' habit of thinking the problem independently, so that all students participate in teaching, to explore. The same question to change the different angles to ask questions, so that students think independently; in the teaching deliberately introduce the wrong view, establish the opposite, triggering students of independent thinking habits and interests. In the way of lectures, pay attention to the introduction of the concept of examples, and eventually return to the idea of mathematical applications, to strengthen students' awareness in application of mathematics and ability. Now, multimedia technology and network tools in mathematics teaching has been widely used. The traditional teaching methods of writing on the blackboard so that students keep up with the teachers' ideas, more conducive to teachers to gradually analyze the problem to explain the problem through. Therefore, in mathematics teaching, the traditional teaching methods cannot be completely lost, to be combined with modern teaching methods to achieve a better teaching effect. Some of the content on the blackboard is difficult to show the content, you can use the multimedia courseware animation to show, to students to create a more comprehensive and unique learning environment. Such as the dynamic formation of spatial surfaces, the use of multimedia screen display, not only to enable students to deepen understanding, but also help to improve student interest in learning. 


\section{Summary}

Higher mathematics education is a rational education, not only can improve the overall quality of people, but also to give people a special thinking quality. For students of economic and management specialty, have good math quality, both to make them better use of scientific thinking methods to observe things, analyze problems, solve problems, but also can improve their application ability and innovative spirit, better to play their talents. With the improvement of the higher mathematics teaching reform of the economic and management specialty and the proper application, it will help to raise the awareness of the higher mathematics teaching of the economic and management specialty, improve the teaching methods and means, improve the teaching quality, fully mobilize the teachers' students' potential and enthusiasm for learning have played an important role. Through the study of higher mathematics, not only the economic management of professional students both literary and artistic, and they can be trained to become a high-quality compound economic and management professionals, which is in line with the current social demand for talent.

\section{Acknowledgements}

The author would like to thank all the editors. Research was supported by Teaching Reform Funding 'Study on Reform of Course-Higher Mathematics' granted by Capital University of Economics and Business 2017.

\section{References}

[1]. Lan Li, Research progress of higher mathematics teaching reform, College Mathematics, Vol. 23, No.4 (2007) 20-26.

[2]. Shuyi Xiao, Research report on teaching reform of higher mathematics, Mathematics Bulletin, 2002(9), 4-9.

[3]. Louis M Friedlwer, Calculus teaching in America 1940-2004, Research on Higher mathematics, 2005 8(3), 6-11.

[4]. Biyu Li, Xuli Han, Xuanyun Qin, and etc., Reform and Practice on Engineering mathematics, Engineering Mathematics, 2000 16(6), 47-49.

[5]. Dianzhou Zhang, For Future: Mathematics education of China in 2010, Mathematics teaching, 1999(1), 1-2.

[6]. Shengwen Li, Xiaoping Zhu, Discussion on teaching reform of combination between higher mathematics and mathematical experiments, Higher Construction Education, 2001(3), 35-36.

[7]. Xinying Ma, Practice of experiment in higher mathematics teaching, Engineering Mathematics, 1999(2), 97-99.

[8]. Zhimin Gao, Application in inequality proof problems of primitive function existing theorem, Study on Higher Mathematics, 2003(4), 33.

[9]. Deyan Ma, Proof of abstract function and specific function inequality, Study on Higher Mathematics, 2003(4), 37.

[10]. Jingzhong Mao, Some thinking on teaching definition of higher mathematics, Bulletin of Mathematics Education, 2003, 12(2), 83-84.

[11]. Aiyun Wang, Yan Zhang, Study and Practice on Teaching Reform of Higher Mathematics Courses, Bulletin of Mathematics Education, 2002, 11(2),84-87. 